\title{
A study on phenotypic and genetic correlations between birth weight and other growth traits in teddy goat
}

\begin{abstract}
In present study data available on 20455 kidding and performance records of 5545 Teddy goats and progeny of 406 sires maintained as separate flocks at Livestock Experiment Stations Rakh Ghulaman, Rakh Khariewala and Chak Katora, Punjab, Pakistan was analyzed. The phenotypic, genetic and environmental correlations between birth weight and other growth traits were estimated by Bivariate REML analysis. The estimates of genetic, Phenotypic and environmental correlations between birth weight and weaning weight were $0.61,0.20$ and 0.19 , between birth weight and weight at six months $0.39,0.24$ and 0.23 , between birth weight and weight at nine months $0.25,0.38$ and 0.36 , between birth weight and yearling weight 0.29 , -0.01 and -0.02 , between birth weight and pre-weaning daily gain $0.55,0.31$ and 0.29 , respectively, while the corresponding values for these correlations between birth weight and post weaning daily gain at six months were $0.41,0.15,0.13$, between birth weight and post weaning daily gain at nine months were $0.22,0.17,0.16$, while between birth weight and post weaning daily gain at twelvemonths was $0.29,-0.06$ and -0.09 , respectively. The results indicated a positive correlation of the between birth weight and other growth traits, except yearling weight and post weaning daily gain at twelvemonths, which indicates that birth weight that selection on the basis of birth weight would result in increase in performance at later ages.
\end{abstract}

Keywords: birth weight, genetic correlation, teddy goats, phenotypic correlation, growth traits
Volume 5 Issue 5 - 2017

\author{
ZH Kuthu,' K Javed, ${ }^{2}$ K Awan, ' N Ahmad,2 \\ A Ahad ${ }^{3}$ \\ 'The University of Poonch, Pakistan \\ 'University of Veterinary \& Animal Sciences, Pakistan \\ ${ }^{3}$ Chittagong Veterinary and Animal Sciences University, \\ Bangladesh
}

Correspondence: Zulfiqar Kuthu, Animal Breeding \& Genetics Lab. Faculty of Veterinary \& Animal Sciences, The University of Poonch, Rawalakot, Azad Kashmir, Pakistan, Tel 0092307562 1698, Email zulfiqar031970@gmail.com

Received: July 13, 2017 | Published: August 02, 2017

\section{Introduction}

The Goat (Capra Hiricus) is also called as a poor man's cow. This Livestock specie is important to poor farming community in the developing world, due to its usefulness due to its higher output as compared to inputs, small size and limited shelter requirements. However, it is highly neglected species and very little research in the past has been carried out on different aspects. The scenario has not changed, although the world goat population has increased. Teddy is one important breed of goat in Pakistan and its genetic potential has not been exploited efficiently due to poor knowledge owing to negligence on the part of research workers. There has no serious effort in the past to explore its genetic composition. The genetic composition of a population can be studied by considering the relative importance of heredity and environmental factors affecting the performance of individuals in that population. ${ }^{1}$ The estimates of genetic parameters are helpful in determining the method of selection to predict direct and correlated response to selection, choosing a breeding system to be adopted for future improvement as well as in the estimation of genetic gains. $^{2}$

The potential of genetic improvement largely depends on genetic variation of the trait and its relationship with the other traits. The genetic correlations give the information that genes affecting one trait also affect the other traits, the effectiveness of selection and net genetic progress can be measured when selection is made for more than one trait. The genetic correlations also help in describing the relationship between the sets of genes responsible for the genetic part of the variance in the two corresponding traits. For evaluation of correlated response in a trait when selection is carried on the basis of other related traits the genetic correlation between the two traits becomes much desirable. Therefore, the present study has been designed with the objective to estimate genetic, phenotypic and environmental correlations among birth weight and other production traits. It is expected that the information generated from the present study will help in the development of breeding plans to bring desirable genetic improvement in the Teddy goat breed in Pakistan.

\section{Materials and methods}

Data available on pedigree, breeding and performance records of Teddy goats (both male and female) maintained at three government owned Livestock Experiment Stations Rakh Ghulaman, Rakh Khariewala and Chak Katora was utilized in this study. The data on birth weight, weaning weight, weaning weight, pre-weaning daily gain, weight at six months, weight at nine months and yearling weight were analyzed to estimate the phenotypic, genetic and environmental correlations between birth weight and other growth traits. The data was edited as far as the accuracy and reliability of records was concerned for pedigree information. The edit criteria were the same as reported elsewhere. ${ }^{3}$ The growth traits were analyzed statistically for the estimation of genetic, phenotypic and environmental correlations between birth weight and other growth traits. For this purpose, bivariate analysis was carried out using Restricted Maximum Likelihood (REML) procedure with an Individual Animal Model. The fixed effects for various growth traits in analysis were the same as considered in the univariate analysis. ${ }^{4}$

The various parameters estimated from the bivariate analysis were: 


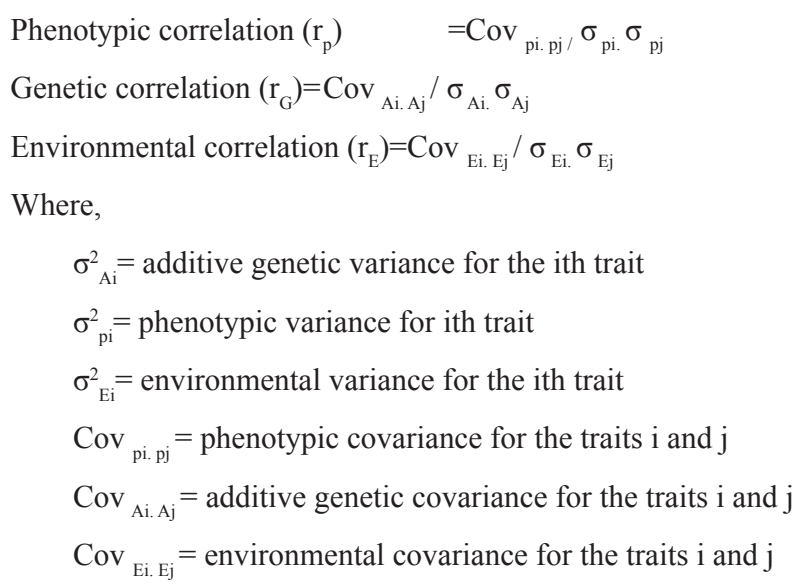

All these analyses were performed by the Restricted Maximum Likelihood method (REML) using the software WOMBAT. ${ }^{5}$

\section{Results}

\section{Genetic and phenotypic correlations}

REML analysis was run for the estimation of genetic, phenotypic and environmental correlations between birth weight and other growth traits (Table 1). The terminology adopted for the discussion of the magnitude of various types of correlations (absolute values) was low $=0.00$ to 0.25 , moderate $=0.26$ to 0.50 , high $=0.51$ to 0.75 and very high $=0.76$ to 1.0 . The estimates of genetic, phenotypic and environmental correlations between birth weight and other growth traits were; with weaning weight $0.61,0.20$ and 0.19 , with weight at six months $0.39,0.24$ and 0.23 , with weight at nine months 0.25 , 0.38 and 0.36 , with yearling weight $0.29,-0.01$ and -0.02 , with pre-weaning daily gain $0.55,0.31$ and 0.29 , respectively, while the corresponding values for these correlations between birth weight and post weaning daily gain at six months of age was $0.41,0.15,0.13$, with post weaning daily gain at nine months of age was $0.22,0.17$, 0.16 , and with post weaning daily gain at twelvemonths of age was $0.29,-0.06$ and -0.09 , respectively.

Table I Correlations between different growth traits

\begin{tabular}{llll}
\hline Trait & Genetic & Phenotypic & Environmental \\
\hline BWT \& WWT & 0.61 & 0.2 & 0.19 \\
BWT \& 6MWT & 0.39 & 0.24 & 0.23 \\
BWT \& 9MWT & 0.25 & 0.38 & 0.36 \\
BWT \& I2MWT & 0.29 & -0.01 & -0.02 \\
BWT \& PrWDG & 0.55 & 0.31 & 0.29 \\
BWT \& PtWDG & 0.41 & 0.15 & 0.13 \\
BWT \& PtWDG2 & 0.22 & 0.17 & 0.16 \\
BWT \& PtWDG3 & 0.29 & -0.06 & -0.09 \\
\hline
\end{tabular}

BWT, birth weight; WWT, weaning weight; 6WT, 6 month weight; 9WT, 9 month weight; PrWDG, pre-weaning daily gain; PtWDGI, post-weaning daily gain at six months; PtWDG2, post-weaning daily gain at nine months; PtWDG3, post-weaning daily gain at 12 months.

\section{Discussion \\ Birth weight and weaning weight}

Most of the reports documented for phenotypic and genetic correlations between the two traits in different goat breeds around the world were in accordance/ comparable with the findings of the present study. The high estimates of genetic correlation between the two traits were also supported by the findings of different workers in different goat breeds around the world. ${ }^{6-11}$ Shafiq \& Sharif ${ }^{6}$ reported that the genetic correlations between birth weight and weaning weight were $0.70 \pm 0.49$ in Teddy goats, while significant genetic $(0.69)$ correlations were also reported between birth weight and weaning weight by Hyder et al. ${ }^{7}$ in Teddy goats.

Low to moderate estimates of genetic correlation between the birth and weaning weight were documented by some researchers. ${ }^{12-23}$ Low phenotypic correlation as found in present study between the two traits were also reported by different researchers. ${ }^{12,17,20,24}$ The high genetic correlation (0.61) between the two traits in present study indicated that both traits are under the influence of similar genes and selection for higher birth weight will result in higher weaning weight as a correlated response. Similarly the phenotypic correlation between the two traits indicated a positive relationship between the traits.

\section{Birth weight and six month weight}

The moderate estimates of genetic correlation between the two traits were in accordance with those findings, which reported that genetic correlations between birth weight and 6months weight in Tellicherry goat kids were $0.378 \pm 0.417 .{ }^{11}$ Moderate genetic correlations between the two traits were also reported by many other workers in different goat breeds around the world., , 17, 19,22 $^{2}$

The moderate genetic correlation between the two traits in present study indicated that these two traits are also under the effect of same genes and selection for higher birth weight will result in moderate increase in weaning weight as a correlated response.

\section{Birth weight and nine month weight}

The findings of present study of low genetic correlation were in partial or full agreement with the findings of many other workers. In a study on Markhoz goat breed of Iran phenotypic, genetic and environmental correlations between birth weight and ninemonth weight were $0.24,0.26$ and 0.25 , respectively. ${ }^{19}$ In Sirohi goats the estimates for phenotypic, genetic and residual correlations between birth weight and nine month weight were $0.28 \pm 0.01,0.43 \pm 0.13$ and $0.26 \pm 0.03 .{ }^{22}$ Genetic and Phenotypic correlations between birth weight and 9months weight in Tellicherry goat kids were $0.291 \pm 0.455$ and $0.256 \pm 0.114$, respectively. ${ }^{11}$

However, different estimates for correlations between the two traits were reported by some other researchers. In Iraqi local goats and their crossbreds with Damascus goats, genetic and phenotypic correlations between birth weight and ninemonth weight were 0.13 and 0.22 , respectively. ${ }^{20}$ The genetic and phenotypic correlations between birth weight and ninemonth weight were 0.461 and 0.398 , respectively, in local goats in Nigeria. ${ }^{21}$

\section{Birth weight and yearling weight}

Different estimates for genetic, phenotypic and environmental correlations between birth weight and yearling weight have been 
reported. The genetic correlations between birth weight and yearling weight using Animal Model were $0.53 \pm 0.18$ and $0.43 \pm 0.28$ for Teddy and Beetal goats, respectively while environmental correlations were 0.71 and 0.67 , respectively. ${ }^{6}$ The genetic and phenotypic correlations between birth weight and yearling weight in Markhoz goats were 0.52 and 0.49 , respectively. ${ }^{15}$ In Kutchi kids, genetic and phenotypic correlations between birth weight and yearling weight were significantly positive and high. ${ }^{25}$ In Sirohi kids, the genetic correlation between birth weight and yearling weight was moderate and negative, while the respective phenotypic association was positive and low. ${ }^{26}$

The phenotypic correlation between birth weight and weaning weight was highly significant and positive in Barbari goat kids. ${ }^{16}$ In Beetal goats phenotypic, genetic and environmental correlations between birth weight and yearling weight using Animal Model were $0.24,0.35 \pm 0.24$ and $0.23 \pm 0.02$, respectively. ${ }^{18}$ Phenotypic, genetic and environmental correlations between birth weight and yearling weight in Markhoz goats were $0.12,0.21$ and 0.22 , respectively. ${ }^{19}$ Genetic correlation $(0.29)$ between the two traits in present study indicated a moderate genetic relationship between the two traits and selection for birth weight in Teddy goats will result in better yearling weight. A negative phenotypic correlation between birth and yearling weight signals a negative relationship between the two traits.

\section{Birth weight and Pre-weaning daily gain}

In literature different estimates of correlation between the two traits have been documented. The genetic correlations between birth weight and pre-weaning daily gains were low in Angora goat kids. ${ }^{27}$ The genetic correlation between birth weight and pre-weaning daily gain was high $(\mathrm{P}<0.05)$, while the phenotypic correlation was also high $(\mathrm{P}<0.01)$ and positive. ${ }^{28}$ In Zaraibi goats of Egypt the genetic and phenotypic correlations between birth weight and pre-weaning daily gain were 0.18 and 0.11 , respectively, ${ }^{17}$ while genetic, phenotypic and environmental correlations between birth weight and pre-weaning daily gain were $0.07,0.47$ and -0.67 , respectively in Teddy goats. ${ }^{7}$ It was reported, that genetic and phenotypic correlations between birth weight and pre-weaning daily gain were 0.51 and 0.442 , respectively, in Nigerian indigenous goats. ${ }^{21}$ The estimates for phenotypic, genetic and residual correlations between birth weight and average daily gain at 0 -3months were $0.17 \pm 0.01,0.20 \pm 0.14$ and $0.18 \pm 0.03$, respectively in Sirohi goat breed of India. ${ }^{22}$ Genetic correlation (0.55) between the two traits suggested a high genetic relationship between the birth weight and pre-weaning daily gain and as a correlated response the selection for birth weight in the Teddy goat breed will result in better growth performance in pre-weaning period.

\section{Birth weight and post-weaning daily gain at 6 and 9months}

The genetic, phenotypic and environmental correlations between birth weight and post-weaning daily gain at six months of age were $0.41,0.15$ and 0.13 , respectively, while the corresponding values between birth weight and post-weaning daily gain at nine months of age were $0.22,0.17$ and 0.16 , respectively. The estimates for phenotypic, genetic and residual correlations between birth weight and average daily gain at $3-6$ months were $0.05 \pm 0.01,0.25 \pm 0.21$ and $0.02 \pm 0.03$, respectively in Sirohi goats. ${ }^{22}$ In present study the moderate estimates (0.41) of genetic correlation between birth weight and postweaning daily gain at six months of age suggested that improvement in birth weight will result in some better growth rate at six months of age, however, its effect on growth rate at nine months of age may not yield the desired results as the genetic correlation between the two traits (birth weight and nine-month weight gain) was low.

\section{Birth weight and post-weaning daily gain at 12 months}

It was found that the genetic and phenotypic correlations between birth weight and post-weaning daily gain were 0.011 and 0.022 , respectively, in Nigerian indigenous goats. ${ }^{21}$ The genetic, phenotypic and environmental correlations between birth weight and post-weaning daily gain at 12 months of age were $0.29,-0.06$ and -0.09 , respectively. The estimates for phenotypic, genetic and residual correlations between birth weight and average daily gain at 6-12months were $-0.01 \pm 0.01,-0.02 \pm 0.56$ and $-0.02 \pm 0.03$, respectively in Sirohi goats. ${ }^{22}$ The moderate genetic correlation between two traits suggests non-antagonism and improvement in birth weight will lead to an improvement in daily gain in 12 months in Teddy goats, however a phenotypic correlation between the two traits signals a slight negative relationship between the two traits, which is undesirable.

\section{Acknowledgements}

The authors thank Director Livestock \& Dairy Development and Incharge/s Livestock Experiment Stations Punjab Pakistan for the willingness for use of data on Teddy goats.

\section{Conflict of interest}

The authors certify that they there are no conflict of interests.

\section{References}

1. Falconer DS, Mackay TFC. Introduction to Quantitative Genetics. UK: Addison Wesley Longman Ltd Edinburg Gate; 1997.

2. Javed K, Abdullah M, Akhtar M, et al. Phenotypic and genetic correlations between first lactation milk yield and some performance traits in Sahiwal cattle. Pakistan Vet J. 2004;24(1):9-12.

3. Kuthu ZH, Javed K, Babar ME, et al. Environmental effects on growth traits of Teddy goats. The Journal of Animal \& Plant sciences. 2013;23(3):692-698.

4. Kuthu ZH, Javed K, Ahmad N, et al. Genetic evaluation of post-weaning growth traits in Teddy goats. Journal of Dairy, Veterinary \& Animal Research. 2015;2(2):00032.

5. Meyer K. WOMBAT- A program for mixed model analyses by restricted maximum likelihood. J Zhejiang Univ Sci B. 2006;8(11):815-821.

6. Shafiq M, Sharif M. Genetic evaluation of goats on productive traits by BLUP procedures. 17th Annual Report, Livestock Production Research Institute, Pakistan; 1996

7. Hyder AU, Khan MS, Akhtar P, et al. Genetic, phenotypic and residual correlation among various performance traits in Teddy goats. Pak Vet J. 2002;22(3):128-130.

8. Unalan A, Cebeci Z. A study on the estimation of genetic parameters of German Fawn X hair crossbred goats. Turkish J Vet Anim Sci. 2001;25(4):527-531.

9. Boujenane I, El-Hazzab A. Genetic parameters for direct and maternal effects on body weights of Draa goats. Small Rum Res. 2008;80(1-3):16-21.

10. Otuma MO, Osakwe II. Estimation of genetic parameters of growth traits in Nigeria Sahelian goats. Res J Anim Sci. 2008;2(3):83-86.

11. Thiruvenkadan AK, Murugan M, Karunanithi K, et al. Genetic and non-genetic factors affecting body weight in Tellicherry goats. South Afr J Anim Sci. 2009;39(1):107-111. 
12. Garcia-Betancourt OJ. Genetic analysis of a cross breeding experiment using improved dairy goat breeds and native goats in a dry tropical environment. Dissertation Abst Inst B. 1982;42(9):3563.

13. Endang TJ. Phenotypic and genotypic parameter estimates for birth weight and weaning weight in Etawah grade goats. In Proc 6th World Conf Anim Prod 563, Finnish Animal Breeding Associations. Finland; 1988.

14. Oka IL, Pattie WA, Restail BJ, et al. Phenotypic and genetic parameters of live weights and growth rates in Australian feral goats. Sustain Anim Prod Environ, In: Proc 7th AAAP Anim Sci Cong. Indonesia; 1994. p. 395-396.

15. Rashidi A, Kashan NE, Miraei-Ashtiani SR, et al. Varaiance-covariance components and genetic parameters estimates for body weights in Markhoz goats. Iranian J Agri Sci. 2000;31(3):455-462.

16. Singh DK, Kumar S, Singh LB, et al. Genetic studies on pre-weaning growth of Black Bengal kids. In Proc 8th National Conf Anim Genet and Breed. India; 2005.

17. Shaat I, Shaaban M, Abdelraheem AA, et al. Estimation of heritability and correlation for milk and growth traits in Zaraibi goats. Egypt J Anim Prod. 2007;44(2):161-171.

18. Ali A, Khan MS. Genetic trends in growth and reproductive traits of Beetal goats. Ind J Anim Genet Breed. 2008;27(1-2):15-25.

19. Rashidi A, Sheikhahmadi M, Rostamzadeh J, et al. Genetic and Phenotypic parameter estimates of body weight at different ages and yearling fleece weight in Markhoz goats. Asian-Aust J Anim Sci. 2008;21(10):1395-1403.
20. Hermiz HN, Alkass JE, Hobi AA, et al. Genetic and phenotypic parameters of body weights in Iraqi local goat and their crosses with Damascus. J Duhok Univ. 2009;12(1):189-194.

21. Alade NK, Dilala MA, Abdulyekeen AO. Phenotypic and genetic parameter estimates of litter size and body weights in goats. Int J Sci Nat. 2010;1(2):262-266.

22. Gowane GR, Chopra A, Prakash V, et al. Estimates of (co)variance components and genetic parameters for growth traits in Sirohi goat. Trop Anim Health Prod. 2011;43(1):189-198.

23. Snyman MA. Genetic parameters for body weight of South African Angora kids and young goats. Grootfontein Agric. 2012;12(1):24.

24. Ekambaram B, Gupta RB, Gnana PM, et al. A Study on the performance of Mahabubnagar goats. Ind J Anim Res. 2010;44(1):48-51.

25. Yadav JS, Rai B, Singh MK, et al. Factors affecting body weights at different ages in flock of Kutchi goats. Ind J Small Rumin. 2003;9(1):53-55.

26. Pathodiya OP, Tailor SP, Gurjar ML, et al. Effects of location, season, sex and genetic group on body weight of Sirohi goats in farmer's flock. In: Proc $8^{\text {th }}$ National Conf Anim Genet Breed, India; 2005.

27. Hermiz HN, Amilv HJAL, Assak EA. Some genetic and non-genetic parameters for pre-weaning growth traits in Angora goats. Dirasat Agri Sci. 1997;24(2):182-186.

28. Mourad M, Anous MR. Estimates of genetic and phenotypic parameters of some growth traits in common African and Alpine crossbred goats. Small Rumin Res. 1998;27(3):197-202. 